\title{
Integrated geophysical and geological investigations applied to sedimentary rock mass characterization
}

\author{
Maria Teresa Carrozzo, Giovanni Leucci, Stefano Margiotta, Fiorella Mazzone and Sergio Negri \\ Osservatorio di Chimica, Fisica e Geologia Ambientali, Dipartimento di Scienza dei Materiali, \\ Università del Salento, Lecce, Italy
}

\begin{abstract}
The Salento Peninsula (south-eastern Italy) is characterized by sedimentary rocks. The carbonatic nature of the rocks means they are affected by karst phenomena, forming such features as sinkholes, collapsed dolines and caverns, as a result of chemical leaching of carbonates by percolating water. The instability of these phenomena often produces land subsidence problems. The importance of these events is increasing due to growing urbanization, numerous quarries affecting both the subsoil and the surface, and an important coastline characterized by cliffs. This paper focuses on geological and geophysical methods for the characterization of soft sedimentary rock, and presents the results of a study carried out in an urban area of Salento. Taking the $Q$ system derived by Barton (2002) as the starting point for the rock mass classification, a new approach and a modification of the Barton method are proposed. The new equation proposed for the classification of sedimentary rock mass $\left(Q_{s r m}\right)$ takes account of the permeability of the rock masses, the geometry of the exposed rock face and their types (for example, quarry face, coastal cliff or cavity), the nature of the lithotypes that constitute the exposed sequence, and their structure and texture. This study revises the correlation between $V p$ and $Q$ derived by Barton (2002), deriving a new empirical equation correlating $P$-wave velocities and $Q_{s r m}$ values in soft sedimentary rock. We also present a case history in which stratigraphical surveys, Electrical Resistivity Tomography (ERT), and seismic surveys were applied to in situ investigations of subsidence phenomena in an urban area to estimate rock mass quality. Our work shows that in the analysis of ground safety it is important to establish the rock mass quality of the subsurface structures; geophysical exploration can thus play a key role in the assessment of subsidence risk.
\end{abstract}

Key words sedimentary rock mass quality - stratigraphy - seismic refraction tomography - ERT

\section{Introduction}

Numerous researchers have developed rock mass classification systems, the validity of which depends on the circumstances. One of

Mailing address: Dr. Giovanni Leucci, Osservatorio di Chimica, Fisica e Geologia Ambientali, Dipartimento di Scienza dei Materiali, Università del Salento, via Monteroni (plesso M), 73100 Lecce; e-mail: gianni.leucci@unile.it the first such systems to be developed is the Rock Quality Designation (RQD) system (Deere, 1963). This system accounts only for the frequency of jointing within a rock mass. Later systems, such as the Rock Mass Rating (RMR, Bieniawski, 1973) and Q systems (Barton et al., 1974), use RQD as one of their measurable parameters, but also include factors such as intact rock strength, joint spacing, joint condition, field stress, number of joint sets and the effects of groundwater. GSI (Hoek, 1994; Hoek et al., 1995; Hoek and Brown, 1997; Marinos and Hoek, 2001) method is based on an assessment of the lithology, structure and condition of discontinuity surfaces in the rock mass and is 
estimated from visual examination of the rock mass exposed.

Characterization of a rock mass may also use information from geophysical methods, as described in numerous studies. Sjogren et al. (1979) correlated $P$-wave velocities with mechanical rock parameters such as fracture frequencies and RQD.

Boadu and Long (1996) proposed a fracture model called «Modified Displacement Discontinuity» (MDD) for seismic wave propagation in fractured media. The model takes into account fracture size, fraction of surface areas in contact, viscosity of infill material and fracture aperture. Boadu (2000) studied empirical least squares regression relationships between seismic wave velocity and the permeability and porosity of fractured media. Kahraman (2002) analysed experimental polynomial relation- ships between Fracture Roughness Coefficient (FRC) and $P$-wave velocity. Barton (2002) proposed an empirical correlation between the $\mathrm{Q}$ factor and $P$-wave velocity based on data from hard rock tunnelling projects in several countries. However, since each technique is generally considered individually in a specific context, it is difficult to compare the results because of different field conditions.

\section{Method}

Subsidence risk analysis is a complex decision-making problem, in which the available information is uncertain and imprecise and knowledge is incomplete. The proposed methods can help overcome these limitations because they adopt a multidisciplinary approach
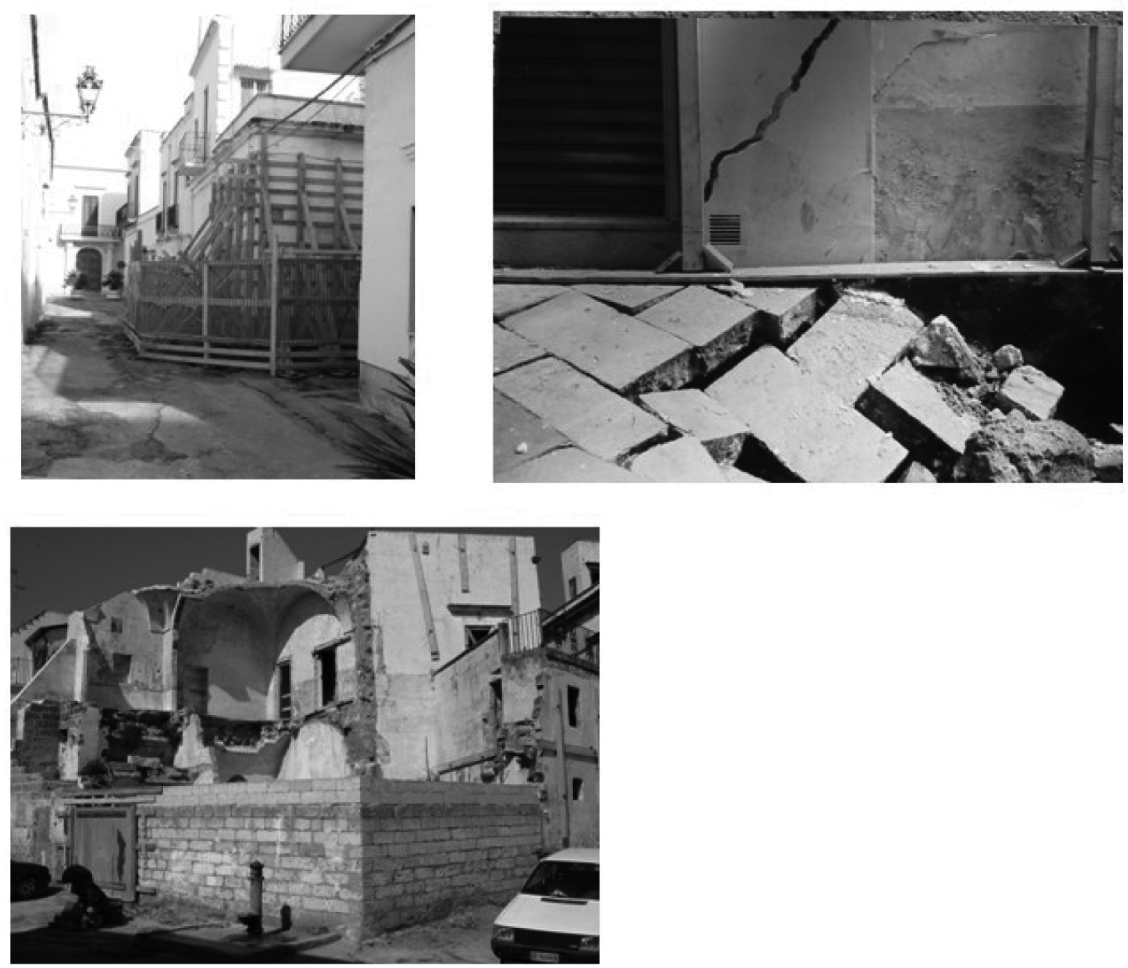

Fig. 1. Photos of soil subsidence in urban areas. 


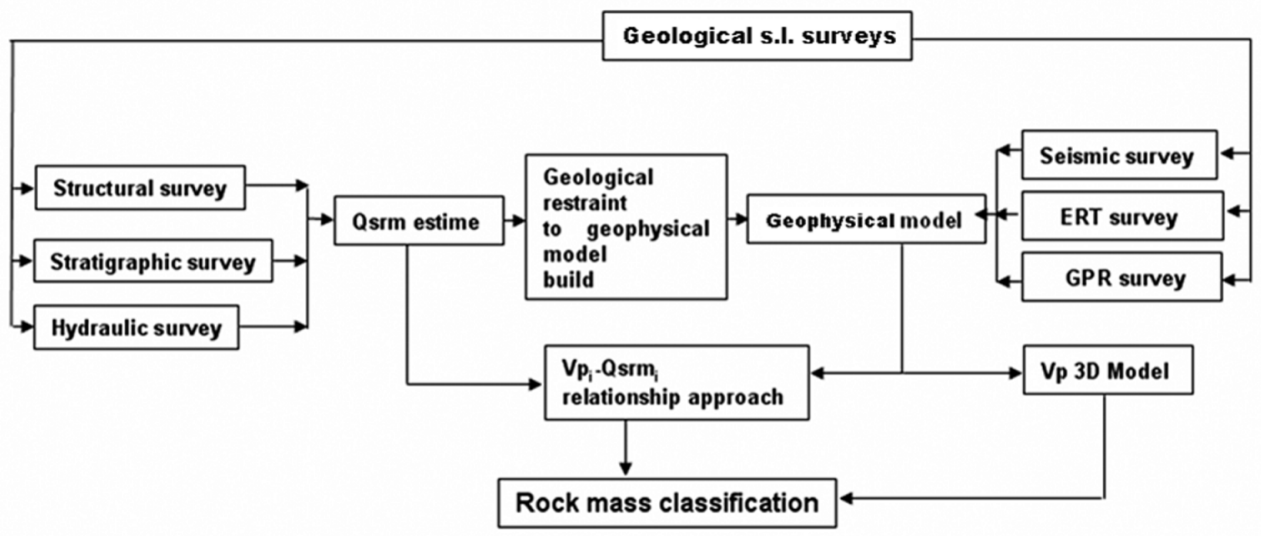

Fig. 2. Flowchart of methods to evaluate rock mass quality.

to managing these aspects and lead to the quantitative characterization of rock mass, which is the primary objective in the study of areas subject to ground subsidence, collapse and instability problems (fig. 1). The general principle underlying these methods is shown in fig. 2:

- preliminary geological sensu latu (s.1.) investigations are important to define the problem (depth of investigation and necessary resolution for geophysical investigations);

- stratigraph, structural and hydraulic investigations for the direct estime of $Q_{s r m}$;

- geophysical investigations that together the geological investigations allow a physical characterization with particular reference to the $V p$ variations;

- the geological investigation sets some geological ties that can be used in the geophysical data interpretation;

- build a 3D model of $V p$ distribution in the subsoil;

- use the empirical relationship between $V p$ and Qsrm for 3D rock mass characterization and classification.

We refer to Barton (2002) as the starting point for rock mass classification and propose a multidisciplinary approach, including geological and geophysical investigations, to the quantitative evaluation of sedimentary rock mass quality, modifying the calculation of both the $Q$-value (2.1) and the correlation of $Q$ with $V p$ (2.2) for sedimentary rock. This method better than others works is adapted in areas where combined geological and geophysical surveys are required in plane areas where rock exposure is insufficient.

The rock mass classification of Barton's $Q$ system is defined by the following relationship:

$$
Q=\frac{\mathrm{RQD}}{J_{n}} \times \frac{J_{r}}{J_{a}} \times \frac{J_{w}}{\mathrm{SRF}}
$$

where RQD is the percentage of competent drillcore sticks $>100 \mathrm{~mm}$ in length in a selected domain, $J_{n}$ is the rating for the number of joint sets, $J_{r}$ is the rating for the roughness of the least favourable of these joint sets or filled discontinuities, $J_{a}$ is the rating for the degree of alteration or clay filling of the least favourable joint set or filled discontinuity, $J_{w}$ is the rating for the water inflow and pressure effects (which may cause outwash of discontinuity infillings), and SRF is the rating for faulting, strength/ stress ratios in hard massive rocks, squeezing or swelling. The rock mass is classified on the basis of the $Q$ value, which can vary from 1000 to 0.001 , by nine classes, from «exceptionally good» $(Q=1000)$ to «exceptionally poor» $(Q=0.001)$. For more information see Barton (2002).

Based on data from «hard rock» tunnelling projects successively extended to include several rock engineering projects in various countries, Barton (2002) correlated the $Q$ values and $P$-wave velocities as follows: 


$$
V p \approx 3.5+\log _{10} Q
$$

This relationship is appropriate for its original applications. On the contrary, great care must be taken when applying rock mass classifications to other rock engineering contexts. In addition, an adjustment for uniaxial compression strengths different from a typical hard rock (100MPA) or more is made by the following simple normalisation of the rock quality $\mathrm{Q}$ value:

$$
Q_{c}=Q \times\left(\sigma_{\mathrm{c}} / 100\right)\left(\sigma_{\mathrm{c}} \text { expressed in MPA }\right)(2.1 \mathrm{a})
$$

Thus we have the following approximation for $V_{p}$

$$
V_{p} \approx 3.5+\log _{10} Q_{c}(\mathrm{Km} / \mathrm{s})
$$

Even if testing with soft rocks has shown that the modified $Q_{c}$ term gives satisfactory fit (Barton, 2006), the aim of this paper is to present a rock mass classification system which is appropriate for the assessment of stability in sedimentary rocks. Sedimentary rocks present specific features such as layers and grain size, which must not be neglected in the characterization of rock quality. This paper focuses on problems of subsidence and collapse in the context of quarry faces, coastal cliffs and manmade or natural caverns, all of which require slightly different approaches from that of Barton (2002). In this paper we propose the following equation based on the observation of about 105 records of exposed (mainly soft) rock faces, to calculate the sedimentary rock mass quality

\section{$Q_{s r m}=\mathrm{RQD} / J n \times J r / J a \times J w / \mathrm{SRF} \times R s / S \times T / V(2.3)$}

For RQD, line mapping or area mapping provides a better picture of the rock mass than cores (Milne et al., 1998; Palmström, 1982); in addition, area mapping provides a three-dimen- sional picture of joint spacing. It remains necessary however to estimate RQD, which Palmström (1982) calculates as follows:

$$
\left\{\mathrm{RQD}=115-3.3 \times J_{V}\right.
$$

Where $J_{v}$ is the number of joints present in a cubic metre of rock. Palmström (1982) estimated $J_{v}$ as

$$
J_{V}=\sum\left(1 / S_{i}\right)
$$

where $S_{i}$ mean joint spacing in metres for the $i$ th joint family.

The PalmstrÖm approach, used in this paper, averages out some of the anisotropy in the RQD value and gives a more representative value.

$J_{n}, J_{r}$ and $J_{a}$ have the meaning proposed in the Barton method. $J_{w}$ and SRF have been modified to adapt them to the geological conditions considered in this paper: $J_{w}$ is the rating for the effects of water flow and pressure, and thus in our system takes account of the permeability of the rock masses. SRF takes account of particular stress reduction factors and we have added others as the geometry and type of the exposed rock face (quarry, cliff, cavity).

In eq. (2.3) four further factors $\left(R_{s}, S, T\right.$ and $V$ ) have been introduced to take account of other features of sedimentary rocks (bedding, lithological types, presence of cavities). $R_{s}$ is the rating for the bedding: massive rock is distinguished from stratified rock; in many cases the layer boundaries are more important in the $Q_{s r m}$ evaluation than fractures or faults because they constitute extended preferential surfaces of weakness and drainage where karst and slumping phenomena can occur. $S$ is the rating for dipping of the layers; where weak planar bedding planes are present in an unfavourable orientation with respect to the rock face, these will dominate the rock mass behaviour. For example

Table I. $Q_{\text {srm }}$ classification sytem.

\begin{tabular}{l|c|c|c|c|c|c|c|c|c}
\hline \hline$Q_{s r m}$ value & $>40000$ & $40000-1000$ & $1000-400$ & $400-100$ & $100-4$ & $4-1$ & $1-0.01$ & $0.01-0.0001$ & $<0.0001$ \\
Class & I & II & III & IV & V & VI & VII & VIII & IX \\
Description & $\begin{array}{c}\text { Exceptionally } \\
\text { good }\end{array}$ & $\begin{array}{c}\text { Extremely } \\
\text { good }\end{array}$ & Very good & Good & Fair & Poor & Very poor & $\begin{array}{c}\text { Extremely } \\
\text { poor }\end{array}$ & $\begin{array}{c}\text { Exceptionally } \\
\text { poor }\end{array}$ \\
\hline
\end{tabular}


consider the dip of rock bedding planes in a costal cliff profile: if the planes dip steeply seaward then sloping cliffs will occur, if they dip vertically, a sheer cliff face will be formed. $T$ is the rating for the texture of the rock mass; we take account of whether the rock mass is composed of a sequence of different rock types or is homogeneous: particular attention is paid to the presence of interbedded layers of clay. $V$ is the rating for the presence of cavities, which in karst areas are also highly important.

See fig. 9 for the details of all factors.

Given the sedimentary nature of the rock masses, the case histories show that the variability of the two ratios $\left(R_{S} / S\right.$ and $\left.T / V\right)$ is comparable with that of the other structural and hydrogeological factors. The two new ratios range from 10 to 0.1 . On the basis of the 105 records the Barton's nine classes of rock quality have been maintained, modifying only the range for each class. Table I summarizes the new rock quality classes based on the $Q_{\text {srm }}$ parameter.

These considerations mean that eq. (2.2) also requires modification. The value $3.5 \mathrm{~km} / \mathrm{s}$ attributed by Barton to poor $(Q=1)$ hard rock, observed in hard rock, is not comparable with the range of Vp typical of highly fractured sedimentary rock investigated by the authors (0.6$2.2 \mathrm{~km} / \mathrm{s}$ ).

Therefore the authors propose a more general relationship than eq. (2.2)

$$
V p=V_{0}+k \log _{10}\left(Q_{s r m} / Q_{0}\right)
$$

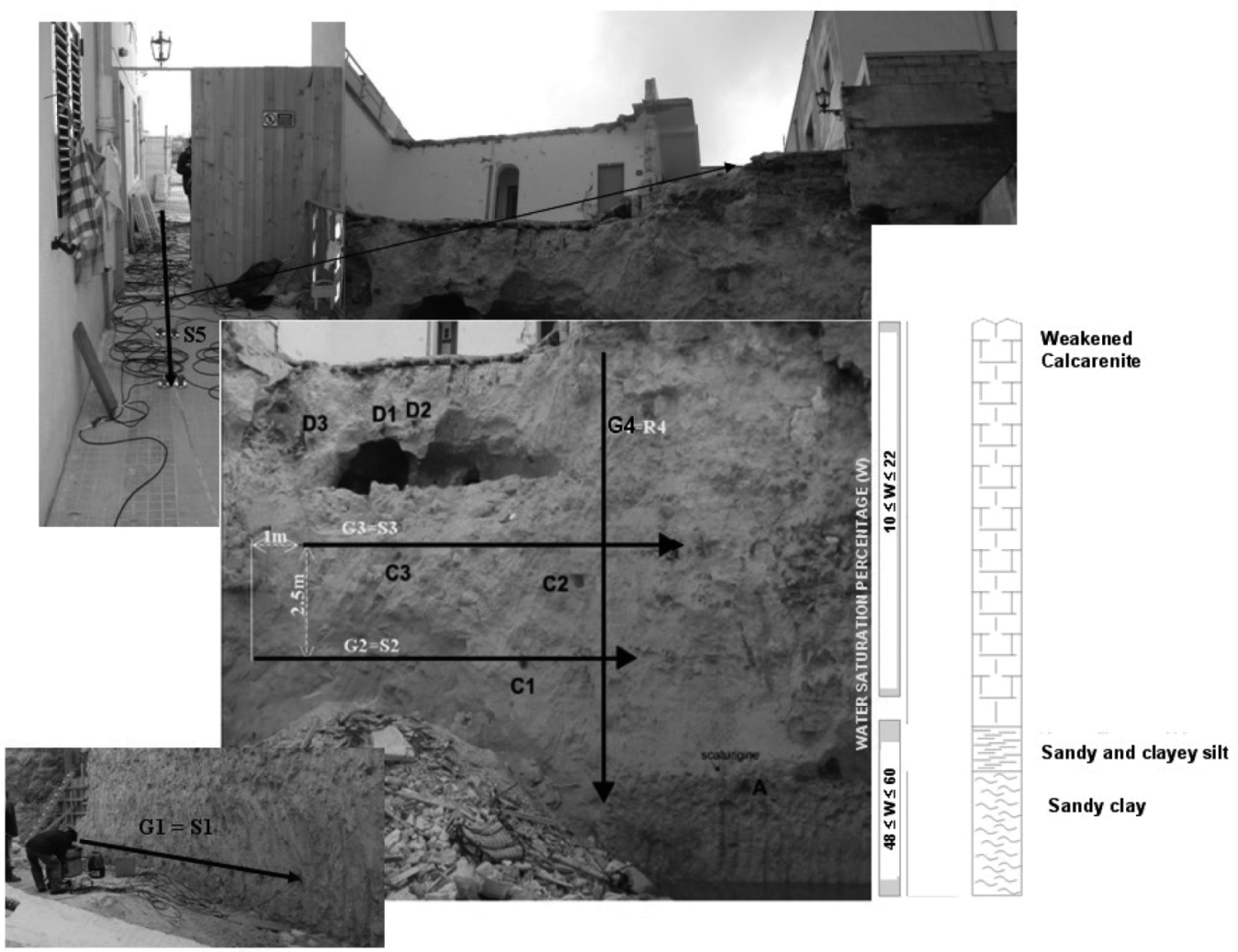

Fig. 3. Exposed rock face in Otranto with stratigraphy and the geophysical profiles location 
where $V_{0}$ is a $P$-wave velocity value characteristic of the subsoil volumes with $Q_{s r m}=Q_{0}$. The factor $k$ depends noticeably on the degree of the water content.

\section{Case study: the methodology application in an urban area}

The following considers an example of the relatively frequent subsidence phenomena occurring in Salento.

For the complexity of the problems it is evident that any geological and/or geophysical methods not would be exhaustive if singly used. In this light, integrated geophysical (with seismic and ERT methods) and geological investigations were undertaken. As already confirmed, before proceeding to the evaluation of the quality of any mass rock is necessary to characterize it.

In the case history we successfully used eq. (2.3) and eq. (2.6) to delineate areas of weak rock mass.

In 2006, in the city of Otranto, located on the eastern side of the Salento peninsula, a house collapsed killing one of the occupants (fig. 3).

The house collapsed following excavation of the slope below it, exposing a rock face of roughly $10 \mathrm{~m}$ in height, enabling the stratigraphy to be studied visually and core samples to be taken at various depths (fig. 3).

\subsection{Rock mass characterization}

The sequence consists of massive calcareous sands with variable silt and biomicrite content overlying sandy and clayey silt and sandy clay. The rock mass is affected by fractures with unaltered and discontinuous joints. Permeability is highest in the calcareous sandy deposits (Uggiano la Chiesa Formation, Pliocene): the higher the proportion of silt, the lower the permeability of the deposit. The lower section of the aquifer, characterized by the presence of sandy and clayey silt sediments, has a lower permeability. In the lower part of the exposed rock face, the low-permeability sediments form the impermeable base of the aquifer.

The rock face contains a man-made cavern

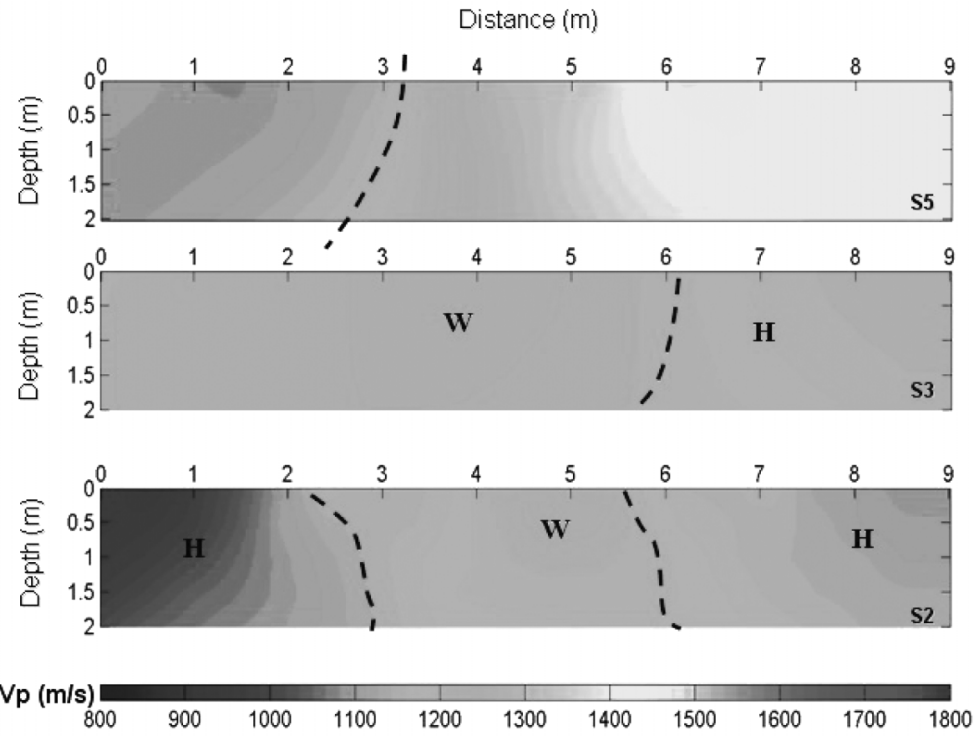

Fig. 4. $P$-wave velocity models. 


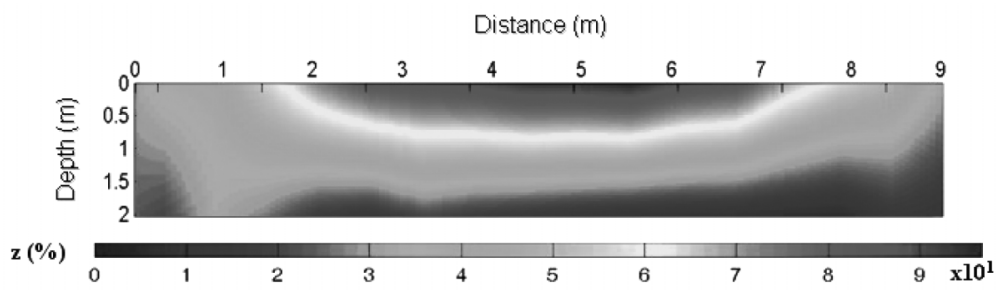

Fig. 5. distribution of ray path density values $z$.

whose roof is located about two metres below the floor of the house.

Geophysical surveys were conducted to obtain more detailed information regarding the exposed rock face. The seismic, and ERT survey lines were superimposed and are shown in fig. 6, labelled $\mathrm{S}$ and $\mathrm{G}$, respectively. The $\mathrm{G} 2$, G3, S2 and S3 profiles were acquired in the zone with a degree of water saturation ranging from $16 \%$ to $22 \%$. The G4 profile was acquired in such a way as to cover two zones with different degrees of water saturation (10-16\% and 16-22\%) (fig. 4).

The energy source for seismic refraction tomography was a sledgehammer striking a steel plate; the recording array was constituted by 10 vertical geophones $(100 \mathrm{~Hz})$, spaced $1 \mathrm{~m}$ apart, and a shot-point near each geophone position. The measurements were collected using a Geometrics Strataview Seismograph (Ninbus 1220 model), with 10 active channels. Seismic profiles labelled S2 and S3 were superimposed on the ERT profiles G2 and G3 respectively. Seismic profile $\mathrm{S} 5$ was acquired near the collapsed house (fig. 3).

In the non-linear inversion method, the velocity model is represented by square cells. The width of each cell is chosen as the receiver interval. First-arrival travel times and ray paths are calculated by the ray tracing method, based on Huygen's principle (Nolet, 1987).

The model relative to each profile was constructed by Simultaneous Iterative Reconstruction Technique (SIRT) using Reflexw software (Sandmeier, 2002).

The first step in the refraction tomography survey consists of measuring the travel times of seismic wave first arrivals in relation to the source-receiver distances located along the profile.

Starting from the model synthetic travel times are calculated. The start model (in this case homogeneous) will be generated automatically when starting the tomography The synthetic travel times are compared to the real ones. Model changes are automatically derived from the travel time residuals.

The results of the inversion of seismic data are shown in fig. 4.

For interpretation purposes, it was important to find representative zones within the $V p$ models. Therefore the ray density $z$ was analyzed.

$z$ describes the reliability of the velocity $V p$ at each grid point and varies between $0 \%$ (uncertain) and $100 \%$ (certain).

The distribution of ray path density values $z$ (fig. 5) giving an idea of the confidence of the calculated grid velocities. It is possible to note the high density (about 90\%) in the central part of the profile.

The S5 profile (fig. 4a) shows that the subsoil may be divided into two main areas. The first (between the abscissa 0 and $3.5 \mathrm{~m}$ ), where seismic velocities, ranging from about $0.9 \mathrm{~km} / \mathrm{s}$ to about $1.1 \mathrm{~km} / \mathrm{s}$ were detected, corresponds to the area near the collapse. These velocity values are typical of highly weathered subsoil (Leucci, 2004).

The second area (between the abscissa 3.5 and $9 \mathrm{~m}$ ) is characterised by higher seismic velocities (ranging from about $1.2 \mathrm{~km} / \mathrm{s}$ to about $1.5 \mathrm{~km} / \mathrm{s}$ ). This increase in seismic wave velocity could be due to the presence of more com- 
(a)

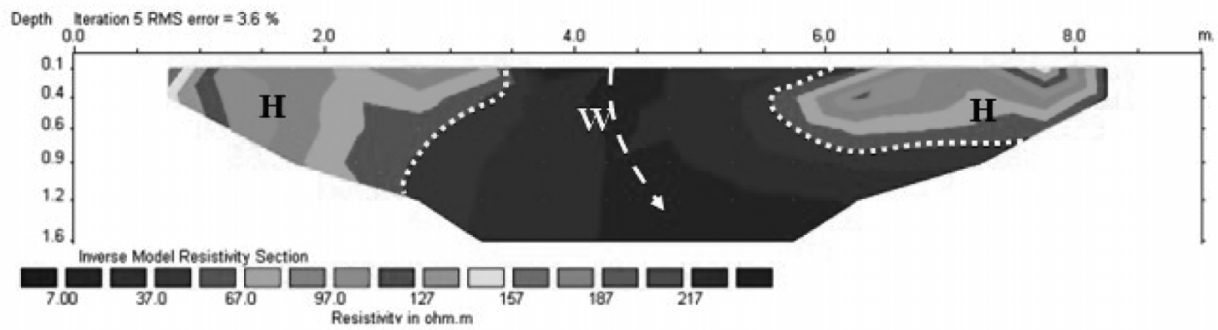

(b)

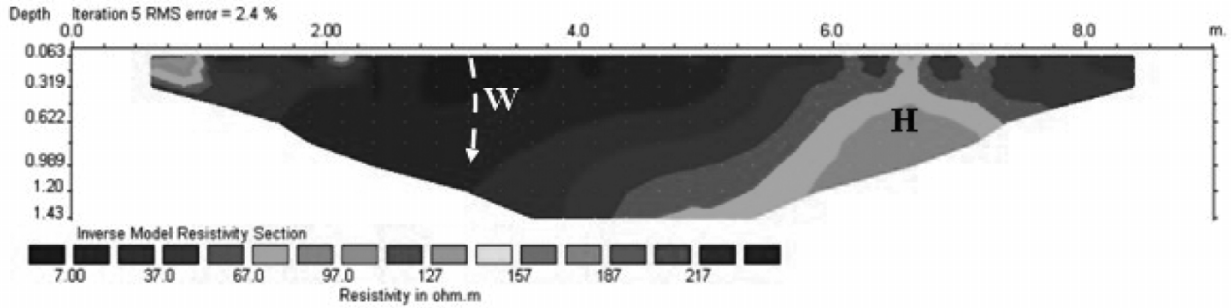

(c)

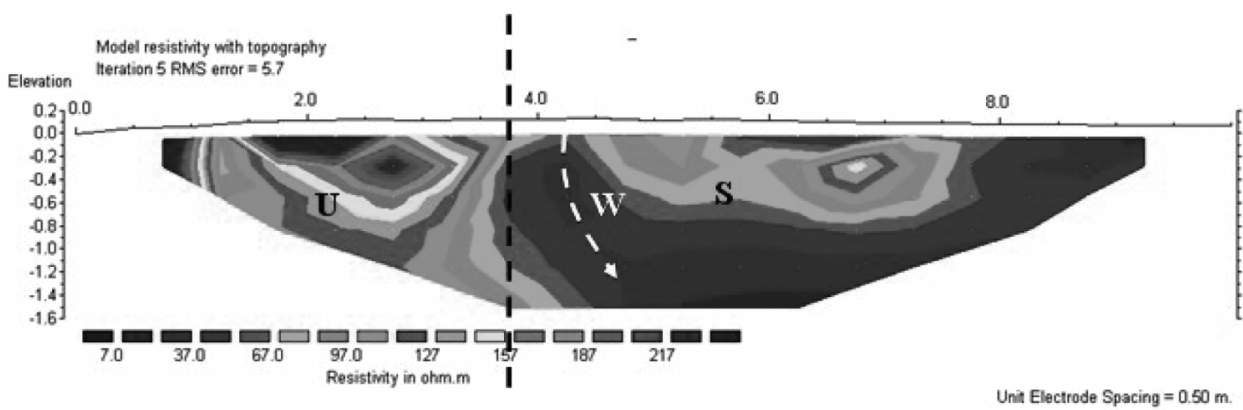

Fig. 6a-c. ERT models relating to profiles G2 (a), G3 (b) and G4 (c).

pact soil or to concrete structures and/or to higher water content in the soil, possibly due to water pipe leakage.

Figures $4 \mathrm{~b}$ and $4 \mathrm{c}$ show the distribution of $P$-wave velocity in the subsoil along the profiles S3 and S2 respectively. The two models are fairly similar.

Figure $6 \mathrm{c}$ shows an area labelled $\mathrm{W}$ of high $P$-wave velocity (from about 1.2 to $1.3 \mathrm{~km} / \mathrm{s}$,), bounded by two areas labelled $\mathrm{H}$ of low $\mathrm{P}$-wave velocity (from about 0.8 to $1.1 \mathrm{~km} / \mathrm{s}$,). The patches labelled $H$ have $P$-wave velocities that indicate poor quality rock.

The seismic profile interpretation alone does not explain whether the $V p$ variations were related to the different water content or rock compaction, but this ambiguity can be resolved combining the ERT and seismic profiles.

The ERT survey was conducted with a Syscal R1 (Iris), using a Wenner array of 19 electrodes for the G2 and G3 profiles and 21 electrodes for the $\mathrm{G} 4$ profile, with a dipole spacing of $0.5 \mathrm{~m}$. Res2dinv software, developed by Loke (2001), was used for data processing and to obtain twodimensional resistivity models of the subsoil. A typical image from the ERT surveys is shown in fig. 6a, which presents a resistivity model for the $\mathrm{G} 2$ profile. In the middle (between 3 and $6 \mathrm{~m}$ on the abscissa) there is an area of low resistivity (about 7 to $60 \Omega \mathrm{m}$ ) labelled $W$, bounded by two 


\begin{tabular}{|c|c|c|c|c|c|}
\hline \multicolumn{6}{|c|}{$Q_{\text {srm }}$ VALUE } \\
\hline joint set 1 spacing & joint set 3 spacing & & JW (Joint Water reduction fact or) & \multicolumn{2}{|c|}{$\mathrm{Jw}$} \\
\hline joint set 2 spacing & joint set 4 spacing & & A Im perm eable or with $m$ edium -low perm eabilityrocks $(K>1 * 10$ & 1 & \\
\hline$J \mathrm{~V}=\Sigma(1 / \mathrm{J}$ oint sets spacing $)=$ & \multicolumn{2}{|l|}{4.00} & 5 and $<1 * 10^{-9}$ ) & & \\
\hline$R Q D=\left(115-\left(3.3^{*} \mathrm{Jv}\right)\right)=$ & \multicolumn{2}{|l|}{101.80} & $\begin{array}{l}\text { B Porous rocks having medium - high perm eability (with } \\
K>1 * 10^{-2} \text { and }<1 * 10^{-5} \text { ) and holding groundwater bodies }\end{array}$ & 0.66 & \\
\hline Jn (Joint Set Number) & \multicolumn{2}{|l|}{$\sqrt{n}$} & C Dryrocks with water flow in joints (outwash ofjoint fillings) & 0.2 & \\
\hline A Massive, no or few joints & \multicolumn{2}{|l|}{0.1} & D Karstic and fractured rocks having high perm eability & 0.5 & \\
\hline $\begin{array}{l}\text { B One joint set } \\
\text { COne joint setplus random joints }\end{array}$ & $\frac{2}{3}$ & \multirow{2}{*}{3} & $\begin{array}{l}\text { E Exsurgence along the rockface of aquifer form ed by } \\
\text { perm eable rocks overlying imperm eable one }\end{array}$ & $0.2 \_0.1$ & 0.1 \\
\hline D Two joint sets & 4 & & F Dryrocks with water flow in unfilled joints & 0.5 & \\
\hline E Two joint sets plus random joints & 9 & & & \multirow{2}{*}{\multicolumn{2}{|c|}{ SRF }} \\
\hline F Three joint sets & 6 & & SRF(Stress Reduction Fact or) & & \\
\hline G Three joint setsplus random joints & 12 & & \multirow{2}{*}{\multicolumn{3}{|c|}{$\begin{array}{l}\text { Weakness zones intersecting excavation, which may cause loosening ofrock } \\
\text { mass }\end{array}$}} \\
\hline H Four or m ore joint sets, random, heavilyjointed & \multirow{2}{*}{\multicolumn{2}{|c|}{15}} & & & \\
\hline <Sugar cube> & & & \multirow{2}{*}{$\begin{array}{l}\text { A Multiple oc currences ofweakness zones containing clayor } \\
\text { chemic allydisintegrated rock, veryloose surrounding rock(any } \\
\text { height) }\end{array}$} & \multirow[b]{2}{*}{10} & \\
\hline ICrushed rock, earthlike & 20 & & & & \\
\hline Jr(Joint Roughness Number) & \multicolumn{2}{|l|}{$\mathrm{Jr}$} & & & \\
\hline (a) Rock - wall contact, and (b) rock - wall contactbefore $10 \mathrm{c}$ & msear & & disintegrated rock(height ofrockface less than $10 \mathrm{~m}$ ) & 5 & \\
\hline A Disc ontinuous joints & 4 & 4 & C Single weakness zones containing clay or chem ic ally & 25 & \\
\hline B Rough or irregular, undulating & 3 & & disintegrated rock(height of ockface $\mathrm{m}$ ore than $10 \mathrm{~m}$ ) & 2.5 & \\
\hline C sm ooth, undulating & 2 & & D Multiple shear zones in com petentrock (clayfree), loose & & \\
\hline D Slickensided, undulating & 1.5 & & surrounding rock(anyheight) & 7.5 & \\
\hline E Rough or irregular, planar & 1.5 & & E Single shear zones in com petentrock (clayfree) (height of & 5 & \\
\hline F Sm ooth, planar & 1 & & rockface less than $10 \mathrm{~m}$ ) & 5 & \\
\hline G Slickenside, planar & 0.5 & & F Single shear zones in competentrock (clayfree) (height of & & \\
\hline (b) Norock - wall contactwhen sheared & & & rockface more than $10 \mathrm{~m}$ ) & 2.5 & \\
\hline $\begin{array}{l}\text { H Zone containing claym inerals thickenough to } \\
\text { preventrock-wall contact }\end{array}$ & 1 & & G Loose, open joints, heavilyjointed or sugar cube (anyheight) & 5 & \\
\hline $\begin{array}{l}\text { I Sandy, gravely or crushed zone thickenough to } \\
\text { preventrock- wall contact }\end{array}$ & 1 & & $\begin{array}{l}\text { Weakness zones related to the geometry and nature of the rock face, wh } \\
\text { may cause loosening ofrock mass }\end{array}$ & & \\
\hline & & & HCliffs & 2.5 & \\
\hline Ja (Joint At eration Number) & $\sqrt{a}$ & & J Dipping rockexposures with talus slope at their base & 1 & \\
\hline A Tightlyhealed, hard, non sofening, im perm eable & 0.75 & & K Rockexposures dipping toward inside & $25^{2}$ & \\
\hline flling $\mathrm{A}<1-3 \mathrm{~mm}$ & 0.10 & & LCoastal cliffs with wave - cutplatiform or cave attheir foot & $5 \_20$ & \\
\hline B Unaltered jointwalls, surface staining only $A<1-3$ & 1 & 1 & M Rockm asses parts ofm an-m ade or natural caverns & & \\
\hline C Slightlyaltered jointwalls, non softening mineral & & & exc avated in the subsoil of noturbanized areas & 5-15 & \\
\hline $\begin{array}{l}\text { coatings, sandyparticles, clayfree disintegrated rock, } \\
\ldots \text { A }<1-3 \mathrm{~mm}\end{array}$ & 2 & & $\begin{array}{l}\begin{array}{l}\text { N Rockm asses parts ofm an-made or natural caverns } \\
\text { excavated in the subs oil ofurbanized areas }\end{array} \\
\end{array}$ & $5{ }^{2} 20$ & \\
\hline $\begin{array}{l}\text { D Silty or sandy- clay coatings, sm all clayffaction (non } \\
\text { soffening) }\end{array}$ & 3 & & Om an - made or natural caverns intersecting rockexposure & 5_15 & 10 \\
\hline $\begin{array}{l}\text { E Softening or low friction claym ineral c oatings and } \\
\text { small quantities of swelling clays } A<1-3 \mathrm{~mm}\end{array}$ & 4 & & $\begin{array}{l}\text { Sqeezing zock:plastic flow ofincompetentrock under the influence ofhigh } \\
\text { rock pressure; Swelling rock:chemical swelling activity depending on pr }\end{array}$ & esence & \\
\hline F Sandyparticles, clayfree disintegrated rockA< & 4 & & ofwater & & \\
\hline G Strongly over - cons olidated non - soffening clay & 6 & & P Mild sqeezing rockpressure & $10 \_20$ & \\
\hline m ineral fillings (continuous but $A<5 \mathrm{~mm}$ ) & 6 & & Q Heawsqeezing rockpressure & $55_{-10}$ & \\
\hline H Medium or low over - cons olidation, softening, clay, & 8 & & R Mild swelling rockpressure & $5 \_10$ & \\
\hline mineral fillings (continuous but $A<5 \mathrm{~mm}$ ) & & & s Heawsw welling rockpressure & $10 \_20$ & \\
\hline J Swelling - clayfillings $A<5 \mathrm{~mm}$ & $8 \_12$ & & & & \\
\hline $\begin{array}{l}\text { KLM Zone or bands of dis integrated or crushed rock } \\
\text { and clay (see } \mathrm{G}, \mathrm{H}, \mathrm{J} \text { for description of claycondition) }\end{array}$ & $6 \_12$ & & & & \\
\hline$A>5 \mathrm{~mm}$ & & & $T$ (Texture) & & \\
\hline N Zone or bands of silty- or sandy- clay, sm all clay & 5 & & A Hom ogeneus rockm asses & 5 & \\
\hline fraction (non softening) & 5 & & B Sequence of different com petentrocktpes & 2 & \\
\hline $\begin{array}{l}\text { OPR Thick, continuous zones or bands of clay(see } \\
G, H, J \text { for description of clayc ondition) }\end{array}$ & 10_20 & & $\begin{array}{l}\text { c Heterogeneous rock masses (sequence of rocks with } \\
\text { differentfeatures conglomerates breccias) }\end{array}$ & 0.5 & 0.5 \\
\hline - & Rs & & $\begin{array}{l}\text { D Sequence of com pactrocktypes with interbedded clayey } \\
\text { layers }\end{array}$ & 0.5 & \\
\hline A Mas sive rock & 5 & & & & \\
\hline B Metric layers $>1 \mathrm{~m}$ & 4 & & $V$ (Void in the rock mass) & & \\
\hline C Decim etric to $m$ etric layers $>0,5$ and $<1 \mathrm{~m}$ & 1 & & \begin{tabular}{|l} 
A Rockm asses without void space \\
\end{tabular} & 0.5 & \\
\hline DDecim etric layers $<0,5 \mathrm{~m}$ & 0.75 & & B Rockm asses with percentage ofvoid space $<10 \%$ & 1 & \\
\hline E Laminated & 0.5 & & C Rockm asses with percentage ofvoid space $<50 \%$ & 3 & 3 \\
\hline & & & D Rockm asses with percentage ofvoid space $>50 \%$ & 4 & \\
\hline S(Bedding) & $\bar{s}$ & & E Softening or low friction claym ineral c oatings and sm all & & \\
\hline A Horizontal or absentbedding & 1 & 1 & quantities of swelling clays inflling void space ofrockm ass & 5 & \\
\hline $\begin{array}{l}\text { B Inclined (dip direction dis concordantto rockface dip } \\
\text { direction) bedding }\end{array}$ & 0.5 & & $\begin{array}{l}\text { FCompetentm ineral and/or cons olidated claym inerals inflling } \\
\text { void space of rockm ass }\end{array}$ & 2 & \\
\hline $\begin{array}{l}\text { CInclined (dip direction concordant to rockface dip } \\
\text { direction) bedding }\end{array}$ & 2 & & & & \\
\hline $\begin{array}{l}\text { DInclined (dip direction concordantto rockface dip } \\
\text { direction) bedding m ore than rockface inclination }\end{array}$ & 4 & & $Q_{s m}=(R Q D / J n)^{*}(J r / J a)^{*}(J w / S R F)^{*}(\operatorname{Rs} / S)^{*}(T N)=$ & 1.1 & \\
\hline E Vertical bedding & 5 & & & & \\
\hline
\end{tabular}

Fig. 7. Rock mass quality of Otranto rock face. 
areas of high resistivity (about 70 to $140 \Omega \mathrm{m}$ ), labelled $H$. The low resistivity area (W) corresponds to the fractured Uggiano la Chiesa Formation filled with water. Indeed, this area could be affected by water drainage.

Similar considerations can be made for the resistivity profile shown in fig. $6 \mathrm{~b}$. In fig. $6 \mathrm{c}$, the passage from unsaturated $(U)$ to saturated $(S)$ zones is clearly visible at $3.5 \mathrm{~m}$ on the abscissa.

Is important to note that comparing ERT models (fig. 6a-c) with $V p$ models (fig. 4), in patch $W$, where the $P$-wave velocity is higher, the ERT profile shows low resistivity values. In the $H$ patches, the $P$-wave velocity is low enough to indicate low water content.

\subsection{Correlation between $\mathrm{Q}_{\mathrm{srm}}$ and $\mathrm{Vp}$}

Applying eq. (2.3) to the results of the stratigraphical, structural and hydrological surveys (fig. 7) highlights the generally very low $Q_{s r m}$ values: 1.13 on average.

Fundamental to the determination of this

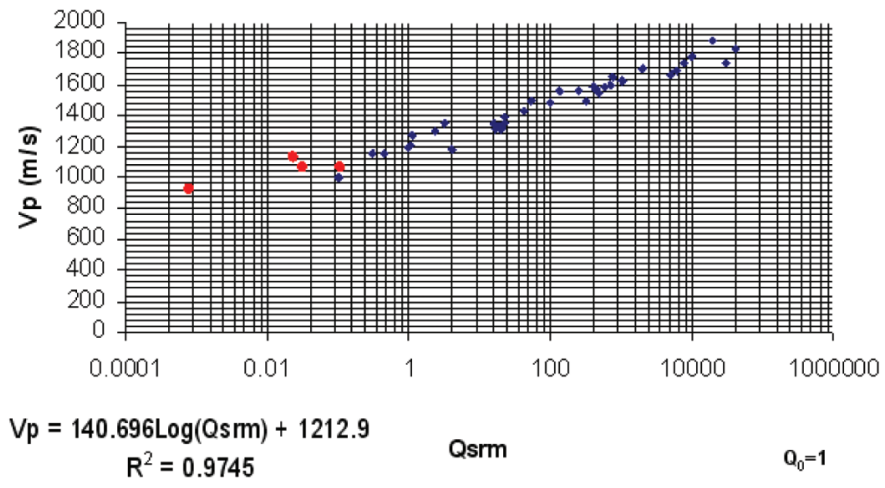

Fig. 8. $P$-wave velocity versus $Q_{s r m}$ factor for coarse-grained massive calcarenite and sandstone of varying coherence (Plio-Pleistocene), permeable due to porosity.

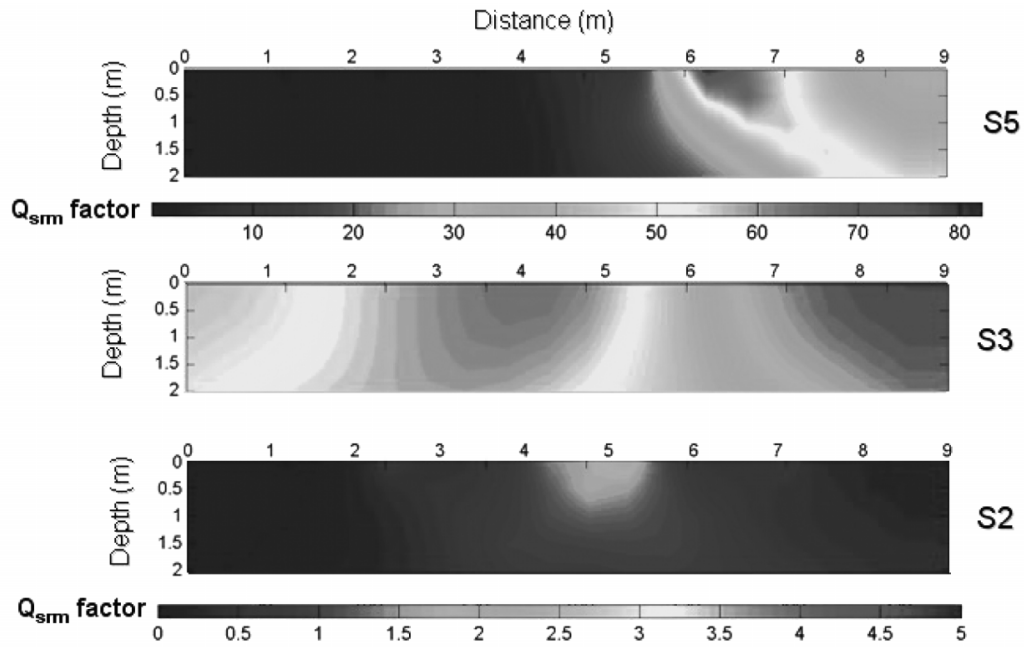

Fig. 9. $Q_{s r m}$-factor models obtained using eq. (2.6). 
value are the heterogeneous characteristics of the rock mass, the cavern and the phreatic groundwater. With reference to table I, this $Q_{s-}$ $r m$ value (1.13) confirms the poor quality of the rock mass, which is thus placed in class VI.

It was necessary to estimate the $V_{0}$ and $k$ values in the studied areas. To improve the statistical value of these measurements, they were enriched with $Q_{s r m}$ and $V p$ values previously measured in similar four geological formations (coarse-grained massive calcarenite and sandstone of varying coherence, Pliocene). The water content degree was less than $25 \%$.

The $P$-wave velocities $(V p)$ were correlated with the $Q_{s r m}$ values and analysed by least squares regression. The best fit line and the correlation coefficient $\left(R^{2}\right)$ were determined with 95\% confidence limits for each regression (fig. $8)$. Red points are related to the correlation between $V p$ and $Q_{s r m}$ data acquired in the same areas; blu points are related to the correlation between $V p$ and $Q_{s r m}$ data acquired in different areas (near between them) but on the same lithology.

This analysis allowed us to estimate the $k$ where the water content degree is less than $25 \%$.

In the regression equations shown in fig. 8, the value of $V_{0}$ was $1212.9 \mathrm{~m} / \mathrm{s}$, the value obtained for $k$ was 140 (if the $P$-wave velocity is expressed in $\mathrm{m} / \mathrm{s}$ ).

On the basis of eq. (2.6), the $Q_{s r m}$ values were recalculated, and the results are shown in fig. 9.

Note that for profile S2 (fig. 9) $Q_{s r m}$ varies from 0.1 to 2.0. For profile S3 $Q_{s r m}$ varies from 1.0 to 4.0. Within these ranges lies the $Q_{\text {srm }}$ value (1.13) estimated from direct visual observation (table I; eq. (3.3)).

The result of seismic profile S5, acquired on the surface is interesting. Note that in the area closest to the exposed rock face $(0-4 \mathrm{~m}$ on the abscissa) the $Q_{s r m}$ values are below 10 and increase with distance from the edge, reaching about 80 (fig. 9). This indicates an improvement in the quality of the rock mass. By analysing the $V p$ variation models (fig. $4 \mathrm{~b}, \mathrm{c}$ ) it is possible to estimate the average $V p$ value and associate it with an average $Q_{s r m}$ value. The result indicates an average $V p$ value of $1210 \mathrm{~m} / \mathrm{s}$ $\pm 8 \%$. From this $V p$ value, an average $Q_{s r m}$ value of $1.2 \pm 0.7 \%$ was obtained using eq. (2.6).

\section{Discussion and conclusions}

This paper focuses on geological and geophysical methods applied to the characterization of softer sedimentary rock and presents the results obtained in a study performed in an urban area of the Salento Peninsula. Referring to the $Q$ system (Barton, 2002) as the starting point for rock mass classification, a new approach, involving a modification to the Barton method, was proposed. The equation proposed for the classification of sedimentary rock mass $\left(Q_{s r m}\right)$ takes account of the permeability of the rock masses, the geometry and type of the exposed rock face, the nature of the lithotypes that constitute the sequence exposed, and their structure and texture.

The relation between $V p$ and $Q$ was modified in order to correlate $V p$ and $Q_{s r m}$ in a manner that was appropriate to softer sedimentary rock. Based on data from seismic surveys conducted in the Salento combined with stratigraphical-structural inspections performed, a new empirical equation correlating $P$-wave velocities and $Q_{s r m}$ values was derived. By means of factor $k$, the new equation takes account of the degree of water saturation and its influence on seismic velocity and consequently on $Q_{s r m}$ values.

Modern techniques for acquiring geophysical data make it possible to carry out two- and three-dimensional tomographies. Considering only the two-dimensional case, the matrix of $V p_{i j}$ values was seen to correspond to a matrix of $Q_{s r m_{i j}}$ values, thus demonstrating the practical importance of estimating the $Q_{s r m}$ value in cells of suitable dimensions, as well as the average $Q_{s r m}$ value in the area under study.

Furthermore the first results of ERT survey performed on the site of Otranto disclosed the potentialities of this method in the characterization of the rocky mass.

In fact essential to the correct use of the eq. (2.6) will be the integration with ERT method, which will be used to distinguish variation of water content and consequently to estime the 
appropriate $k$ value. In the case studied the estimated $k$ value was $140 \mathrm{~m} / \mathrm{s}$ for water content degree ranging from 10 to $22 \%$.

Currently studies are in progress to define the relationships between the various physical parameters measured with geophysical methods (electrical resistivity, dielectrical constant, seismic wave velocity).

The principal limitation of the rock mass classification scheme presented here, as with all such schemes, is its subjective character. However, to transform subjective data into quasi-objective data, major progress in the evaluation of sedimentary rock mass quality is required. The first step is to accurately characterize the rock mass, attributing parameter ratings. In this step, the classification scheme can be used as a check-list to verify that all important information has been considered. The second step is to treat sedimentary rock mass classification as a multidisciplinary issue (in this case involving geologists and geophysicists). The third step is to use this classification scheme in conjunction with site-specific analyses: for example, a rock mass of good quality will have a higher strength and higher deformation modulus than a poor quality rock mass.

In addition, like most classification schemes, the one proposed in this paper has been shown to be appropriate for its original application (sedimentary rock masses), and we recommend its use within the limits of the case histories from which it was developed; great care must be taken when applying this rock mass classification scheme to other rock contexts.

\section{Acknowledgements}

The authors wish to thank referees Prof. Nick Barton and Prof. Dario Luzio for their valuable comments. Our thanks also to George Metcalf for proof-reading the manuscript.

\section{REFERENCES}

BARTON, N. (2002): Some new Q-value correlations to assist in site characterisation and tunnel design, Int. J. Rock Mech. Min. Sci., 39, 185-216.

BARTON, N. (2006): Rock quality, seismic velocity, attenuation and anisotropy, (Taylor \& Francis Balkema).

BARTON, N., R. LIEN and J Lunde (1974): Engineering classification of rockmasses for the design of tunnel support, Rock Mech., 6 (4), 189-236.

BIENIAWSKI, Z.T. (1973): Engineering classification of jointed rock masses, Trans. S. Afr. Inst Civ. Eng., 15, 335-344.

BOADU, F.K. (2000): Predicting the transport properties of fractured rocks from seismic information: numerical experiments, J. Appl. Geophys., 44, 103-113.

BoADU, F.K. and T.L. LONG (1996): Effects of fractures on seismic wave velocity and attenuation, Geophys. J. Int., 127, 86-110.

DEERE, D.U. (1963): Technical description of rock cores for engineering pur pose, Rock Mech. Eng. Geol., 1, 18-22;

HoEk, E. (1994): Strenght of rock and rock masses, ISRM News J., 2 (2), 4-16

Hoek, E. and E.T. Brown (1997): Practical estimates or rock mass strength, Int. J. Rock Mech. Mining Sci. Geomech. Abstr., 34 (8), 1165-1186.

HoEk, E., P.K. KAISER and W.F. BAWDEN (1995): Support of Underground Excavations in Hard Rock (Rotterdam, Balkema).

KAHRAMAN, S. (2002): The effects of fracture roughness on $P$-wave velocity, Eng. Geol., 63, 347-350.

LEUCCI, G. (2004): I metodi elettromagnetico impulsivo, elettrico e sismico tomografico a rifrazione per la risoluzione di problematiche ambientali: sviluppi metodologici e applicazioni, Ph.D. Thesis.

LOKE, M.H. (2001): Tutorial: $2 D$ and 3D Electrical Imaging Survey (http://www.geotomo.com/)

MARINOS. P, and E. HoEK (2001): Estimating the geotechnical properties of heterogeneous rock masses such as flysch, Bull. Eng. Geol. Environ. (IAEG), 60, 85-92.

Milne, D., J. Hadjigeorgiou and PaKalnis (1998): Rock mass characterization for underground hard rock mines, Tunnelling Underground Space Technol., 13 (4), 383-391;

Nolet, G. (1987): Seismic Tomography (D. Reidel Publishing Company, Dordrecht, Holland)

Palmstrom, A. (1982): The volumetric joint count - a useful and simple measure of the degree of rock jointing, in Proc. 4th Int. Congress Int. Ass. Eng., Geol. Dep., 5, 221-228;

SANDMEIER, K.J. (2002): Reflexw 3.0 Manual (Sandmeier Software, Zipser Strabe 1, Karlsruhe, Germany)

SJogren, B., A. Ofsthus and J. SANDBERG (1979): Seismic classification of rock mass qualities, Geophys. Prospect., 27(2), 409-442. 